\title{
FURTHER REMARKS ON THE CARE OF GUNSHOT WOUNDS OF THE ABDOMEN.
}

WITH ESPECIAL REFERENCE TO THE TREATMENT OF WOUNDS OF THE URINARY BLADDER AND THE DANGER OF ABSCESS AND FISTULA FOLLOWING WOUNDS OF THE PANCREAS.

By George Tully Vaugitan, M.D., PROFESSOR OF SURGERY IN THE UNIVERSTTY OF GEORGETOWN, WASHINGTON, D. C.

LAST year $I^{1}$ reported 14 cases of gunshot wound of the abdomen. Since that time I have had 3 more cases, which I desire to report with comments, as 2 of them were of unusual interest.

CASE I. ${ }^{2}$-Ten holes in the small intestine, two in the bladder; resection; permanent catheterization; recovery.

W. H., a colored male, aged twenty-three years, a native of Maryland, a waiter by occupation, was operated on January 27, 1906, at the Emergency Hospital, four hours after having been shot. A 0.32 pistol-ball had entered the abdomen on the right side, one inch to the inner side of the anterior superior spinous process of the ilium. 'The condition of the patient was good; his pulse 96 ; he had vomited once, and had some pain in the bowels, but it was not very severe. Under ether anesthetization the abdomen was opened through the right rectus muscle, revealing considerable thin, bloody fluid, ten holes in the small intestine (ileum) and two in the bladder. The ten holes in the bowel were in a portion of bowel not over two feet in length, and four of the holes were in a section not over two inches long. Six holes were closed with silk sutures; the two inches of bowel so badly lacerated were resected and an end-to-end union made with silk sutures. One opening in the bladder was closed, but the other was so deep in the pelvis as to be inaccessible without opening the bladder and suturing it from the inside. Rather than do this it was decided to provide permanent drainage to the bladder, in order to prevent the escape of urine into the peritoneal cavity; this was done by putting into the bladder, through the urethra, a soft-rubber catheter and fixing it in position. The abdominal incision was closed, leaving a rubber drainage tube in the lower end of the incision. There was suppuration in the abdomen for about three weeks, when it ceased and the drainage tube was removed. The catheter was removed twice a week for cleansing and was left out permanently at the end of three weeks. The patient had no difficulty in urinating. He was permitted to get up March 1, thirty-two days after the operation, and was discharged recovered March 12. 
A skiagram showed the bullet on the left side, apparently just above the neck of the left femur. It was not disturbed.

CASE II.-Nine openings in the small intestine, two in the bladder; operation twelve hours after injury; death.

R. W., colored, male, aged twenty-eight years, was shot March 1 , 1906, the ball entering the back near the spine, just below the left twelfth rib, and was operated on at Georgetown University Hospital March 2, about twelve hours after the injury. Pain did not come on for several hours after the shooting, but when seen twelve hours later the patient was in great pain. The abdomen was swollen and tender; he had passed bloody urine, had vomited once, and the pulse was 110. Under ether anesthetization the abdomen was opened in the median line, just above the pubes. At least three pints (1500 c.c.) of bloody fluid with a fecal odor was found in the peritoneal cavity, and peritonitis was well advanced, the intestines being distended, swollen, and many coils covered with lymph. Nine holes were found in the bowel, distributed through about the last seven feet of the ileum, and two in the bladder, one above the other, about one and one-half inches apart. All the holes were closed with silk sutures, the abdominal cavity was thoroughly irrigated with salt solution and closed with drainage, and a catheter was fastened in the urethra. The ball, 0.32 in calibre, was found loose in the bottom of the peritoneal cavity. Death from peritonitis occurred twentysix hours latcr.

CASE III.-Wounds of the liver, stomach, pancreas, and kidney; primary healing after operation, followed two months later by a second operation for abscess in connection with the pancreas.

Mrs. A. K., a white female, aged twenty-five years, was shot June 25,1906 , and was operated on one and one-quarter hours later at the Emergency Hospital. A 0.32 pistol-ball had entered the epigastric region three inches below the ensiforn cartilage and one inch to the left of the median line; it could be felt beneath the skin on the back, just below the last rib and three inches to the left of the median line. At the time of the operation the patient was in good condition, pain was not severe, the pulse was 100, the skin cool, and she had vomited blood. Under ether anesthetization the abdomen was opened through the left rectus muscle. A bole was found in the left lobe of the liver from which bleeding was still going on, and one in the anterior wall of the stomach. These were sutured at once, the liver with catgut and the stomach with silk. The lesser peritoneal cavity was then opened by bringing up the transverse colon and splitting the mesocolon, thus exposing the posterior wall of the stomach, in which another hole was found and sutured. A hole in the pancreas was sutured; beyond this the ball was not traced, but there can be no doubt that it wounded the left kidney, as the organ lay directly in the path of the bullet, and examination of the urine showed considerable blood which could not otherwise be 
accounted for. No irrigation was used in the toilet of the peritoneum; the blood and clots were simply sponged out and the abdomen was closed without drainage. 'There was no trouble about healing, but the temperature and pulse continued above the normal. On July 27 the ball was removed under cocaine, but no sign of abscess was seen.

On August 25, two months after the operation, the patient was still not well, and during the last two or three weeks she had been getting worse. The temperature had not remained normal for more than a day at any time since the operation, usually ranging from $99^{\circ}$ to $101^{\circ}$, the pulse 90 to 110 , although she had been sitting up and walking about. Recently the temperature had been running higher, $100^{\circ}$ to $103^{\circ}$, the pulse 100 to 120 ; there were no chills, but sweats were common, appetite was poor, constipation was present, and marked loss of flesh had occurred. Physical examination showed tenderness, swelling, and abnormal percussion note. It was thought that an abscess might be present, possibly due to the action of the pancreatic juice, and an exploratory laparotomy was done August 25. The abdomen was opened through the scar. Spider-web adhesions were found, but the wounds in the liver and stomach (anterior) were well healed. On lifting up the transverse colon a hard mass was felt deep in the cavity, behind the lower border of the stomach, bounded above by the pancreas, with which it was attached; to the outer side was the descending colon; to the inner side the inferior mesenteric vein showed promincntly, while also to the inner side, below and in front, was the first portion of the jejunum, just after the intestine escapes from the ligament of Treitz. These parts were adherent, and on breaking up the adhesions a cavity containing about a tablespoonful of yellowish debris was discovered. The stomach did not appear to enter into the formation of the abscess. The broken-down material was wiped out and a rubber drainage tube was put in through a stab wound through to the back, where it was sewed to the skin. The incision in front was closed without drainage. Four days later the pulse and temperature were practically normal and remained so. There was only a slight discharge through the tube until the fourth day, when a large quantity of what looked like pus, and contained staphylococci, was discharged. The discharge continued for five weeks, when it ceased and the opening healed. It was collected in two or three days and amounted to seven ounces in twenty-four hours, and on being tested by Dr. J. F. Anderson, it gave all the reactions of pancreatic juice.

The first 2 cases show quite clearly the importance of early operation. The wounds were almost exactly alike in location and severity, but the one patient was operated on four hours, and the other twelve hours, after the reception of the wound; there was no evidence of peritonitis at the time of operation in the first case, but peritonitis was well under way in the second case and death resulted. 
Another point of interest is the use of the catheter as a drainage tube for the bladder, to prevent the escape of urine into the peritoneal cavity when, for any reason, a wound of the bladder cannot be closed. I generally use it even in wounds of the bladder which have been completely closed, in order to prevent tension while the wounds are healing.

Case III is interesting on account of the pancreatic fistula and its resemblance to the wounds received by President McKinley, in which the bullet passed through the stomach and wounded the pancreas and left kidney, and was followed by the formation of an abscess in connection with the pancreas.

\title{
THE CAUSES AND TREATMENT OF STERILITY IN WOMEN.
}

\author{
By Edward Reynolds, M.D., \\ SURGEON TO THE FREE HOSPITAL FOR WOMEN, BOSTON, MASBACHUSETTS.
}

THE treatment of sterility is mainly. minor office treatment and has long been regarded as one of the most unsatisfactory parts of gynecological practice. That positive results cannot be promised is still true; unsuccessful cases are still met with, and always will be; yet, in point of fact, it is not nearly so discouraging as it has been considered. The subject usually has not been studied in sufficient detail, and the treatment of a given case is too frequently based on an insufficient study of the patient.

Of course, it must be premised at the outset that the fertility of a given marriage is dependent upon the condition of both of the two partners. There has long been a general impression that sterility is exceedingly rare in men and common in women, an erroneous conception which has led, and still leads, to much unnecessary and unfair treatment of perfectly fertile women; but it is as a result of this conception that it is usually the woman who presents herself for treatment.

It is probably true that sterility is somewhat more common in women than in men, and when the woman who comes for treatment presents some minor abnormality which might prevent conception, and which can easily be remedied by painless treatment, it is probably wise to apply such treatment for a reasonable length of time before questioning the condition of the husband; but no extended or uncomfortable treatment should be given, and certainly no operative work, even of a minor nature, should ever be undertaken without first establishing the fertility of the husband. Sterility in men is not, however, the subject of this paper and may, therefore, be dismissed with this preliminary proviso.

Sterility in women may be dependent on many possible causes, 